\section{Perspectivas da Extensão Universitária no Projeto Troca de Saberes da Universidade do Estado de Santa Catarina (UDESC)}

\author{
Prospects of the University Extension related to the Project \\ "Exchange of Knowledges" of Santa Catarina State University
}

\section{RESUMO}

Este artigo aborda a Extensão Universitária em uma experiência de acadêmicos do Centro de Ciências Agroveterinárias (CAV), da Universidade do Estado de Santa Catarina (UDESC), participantes no projeto Troca de Saberes - Grupo de Trabalho para Preparo de Ações Junto ao Núcleo Extensionista RONDON (NER) - UDESC, desenvolvido no Planalto Catarinense. A prática da Troca de Saberes entre a Universidade, através de seus acadêmicos, e a comunidade, contribui para o desenvolvimento socioambiental na área que recebe a aplicação direta da proposta deste trabalho. Mudanças de caráter pessoal, acadêmico e profissional são alcançadas pelos protagonistas dessa iniciativa, os acadêmicos da UDESC. Dessa forma, o projeto toma suas ações como importante ferramenta pedagógica para a prática da cidadania e transdisciplinaridade, tornando-se instrumento político pedagógico para a complementação de uma formação acadêmica baseada em valores e experiências sociais vinculadas à localidade onde o projeto se insere. A gestão participativa é, em muitas situações, providencial para solução de problemas socioambientais para assim alcançar o objetivo comum. Nesse sentido, a extensão universitária circunscrita do Projeto Troca de Saberes atua diretamente para as mudanças socioambientais em suas diversas formas e práticas.

Palavras-chave: Extensão Universitária. Troca de Saberes. Formação Acadêmica.

\section{ABSTRACT}

This article addresses the theme University Extension through the experience of academics Centro de Ciências Agroveterinárias (CAV) of Universidade do Estado de Santa Catarina, participants in the project Exchange of Knowledge developed in the Santa Catarina highlands. The practice of Knowledge Exchange between university students and the community, contributes to socio and environmental development in the area that receives the direct application of this work proposal. Changes in personal,
Guilherme da Silva

Ricardo e Álvaro

\section{LUIZ MAFra}

Universidade do Estado de Santa Catarina. Centro de Ciên cias Agroveterinárias, Santa Catarina, Brasil 
academic and career are achieved by the agents of this initiative, academics UDESC. In this way the project takes your actions as an important educational tool for the practice of citizenship and transdisciplinarity, assuming as an instrument in complementing of a academic formation based on values and social experiences linked to location where the project is inserted. Participatory management is in many situations, providential for solving environmental problems and thus achieve the common objective. In this sense the university extension by Exchange of Knowledge project works directly for environmental changes in their different forms and practices.

Keywords: University Extension. Exchange of Knowledge. Academic Formation.

\section{INTRODUÇÃO}

A ideia de desenvolver o Projeto de Extensão Troca de Saberes na comunidade do entorno do campus III da UDESC, o Centro de Ciências Agroveterinárias (CAV), localizado na cidade de Lages, Santa Catarina, surgiu de experiências em atividades da extensão universitária do Núcleo Extensionista RONDON (NER/UDESC) que desenvolve ações regionais no Estado de Santa Catarina, tendo como principal finalidade atender demandas da sociedade. O NER já atuou em diferentes áreas do território catarinense abrangendo as regiões: Meio Oeste, Extremo Oeste, Planalto e Extremo Sul Catarinense. As diferentes realidades encontradas nas ações do NER, nas quais a academia esteve imersa por dias, em contato direto com a comunidade local, conduziu o olhar para a identificação das demandas socioambientais existentes no contexto em que o campus CAV está inserido.

Trazer a metodologia das ações regionais para o local em que os acadêmicos constroem suas graduações é o objetivo deste projeto, que está amparado teoricamente na literatura de pensadores clássicos como Paulo Freire, e pesquisadores recentes como Munhoz (2009), Bulhões (2010) e Santos (2012). Dessa forma, as análises das demandas socioambientais feitas pelos acadêmicos, professores e gestores da educação do CAV/ UDESC e de outras instituições de ensino confirmam a necessidade de intensificar a participação universitária junto à sociedade sediada ao entorno do campus, com o objetivo de promover o seu desenvolvimento.

Para a academia, buscam-se, nessas experiências, os benefícios de uma complementação na formação do indivíduo que identifica a sua competência e responsabilidade de contribuição direta para a sociedade que financia seu aprendizado. O referencial teórico deste artigo ancora-se em outros autores que identificam a extensão universitária como atividade imprescindível às universidades, estando apoiado na Política de Extensão Universitária da UDESC, regulamentada na resolução No $007 / 2011$ do seu Conselho Universitário.

\section{APRESENTAÇÃO E ORIGEM DO PROJETO}

O Projeto de Extensão Troca de Saberes conta com uma equipe multidisciplinar que desenvolve atividades de natureza transdisciplinar, tendo como base o Plano Nacional de Extensão de 2007, que, por meio do Fórum de Pró-Reitores/as de Extensão das 
Universidades Públicas Brasileiras, estabelece a necessidade de maior relação entre universidade e sociedade [5]. A partir dessa necessidade, o projeto promove a articulação de discentes e docentes dos cursos de graduação em Agronomia, Engenharia Ambiental, Engenharia Florestal, Medicina Veterinária e Pós-Graduação do CAV/UDESC, através de um grupo de estudantes voluntários que se renova semestralmente, atuando em um projeto que tem como pré-requisito o comprometimento com a responsabilidade socioambiental e o interesse em viver experiências como multiplicadores do conhecimento adquirido na universidade. O projeto está situado na região do Planalto Catarinense, que detém os seguintes valores no Índice de Desenvolvimento Humano: Lages/SC - IDH (o,551 em 1991), (o,674 em 2000) e (o,770 em 2010). Atualmente o IDH situa-se ligeiramente abaixo da média estadual que é de 0,774 para ano 2010, segundo o Plano das Nações Unidas para o Desenvolvimento no Brasil (PNUD) [3]. Entretanto, a condição regular, em relação à média estadual, não coloca a cidade em zona de conforto, em função das demandas socioambientais existentes e identificadas neste projeto.

O projeto sai dos limites físicos da universidade por meio da extensão universitária levando, através dos acadêmicos, o conhecimento acadêmico às escolas públicas. Estas, que são importantes espaços de diálogo e portadoras de um conhecimento que é absorvido pelos acadêmicos, uma vez que a Extensão Universitária é uma via de mão dupla, conforme salienta o Fórum Nacional de Pró-Reitores de Extensão das Universidades Públicas Brasileiras [5].

O projeto Troca de Sabres nasceu das experiências com as operações regionais do NER/UDESC organizadas em parceria com cidades interessadas em receber acadêmicos extensionistas voluntários por um período de tempo de operação que tem sido de, aproximadamente, dez dias, sempre ao final dos semestres acadêmicos. Desde a sua criação, em 2010, o NER realizou cinco operações em Santa Catarina: Operação Contestado (2010.2); Operação Fronteira (2011.1); Operação Caminho dos Tropeiros (2011.2) e Operação Serra \& Mar (2012.1); Operação Integração (2013-1) [14]. Nessas ações, o público catarinense contemplado foi maior do que 35.000 pessoas, com participação efetiva de aproximadamente 650 acadêmicos da UDESC e de outras Instituições do Brasil, como a Universidade de Brasília (UnB). A partir da Operação Fronteira (2011.1), o projeto Troca de Saberes começou a ser planejado, tendo suas atividades iniciadas no primeiro semestre de 2012. Além das ações locais que o Troca de Saberes desenvolve junto à comunidade, também orienta os acadêmicos extensionistas já capacitados do ponto vista metodológico, a participarem das operações semestrais do NER, também conhecidas na universidade como "Operações do Projeto RONDON/UDESC”. A UDESC também participa no Projeto RONDON de abrangência Nacional, coordenado pelo Ministério da Defesa, que seleciona acadêmicos de todo o Brasil para suas operações*.

\section{MATERIAIS E MÉTODOS}

O projeto tem suas ações amparadas pela RESOLUÇÃO No 026/2012, do Conselho de Ensino, Pesquisa e Extensão (CONSEPE), que regulamenta as atividades complementares nos Cursos de Graduação da UDESC, segundo Art. $2^{\circ}$ item III**.
*"...] O Projeto Rondon, coordenado pelo Ministério da Defesa, é um projeto de integração social que envolve participação voluntária de estudantes universitários na busca de soluções que contribuam para o desenvolvimento sustentável de comunidades carentes e ampliem o bemestar da população [...]". E ainda: "[...] O Projeto Rondon tem por finalidade levar as Instituições de Ensino Superior e seus estudantes àquelas regiões menos favorecidas do Brasil, para dar-Ihes a oportunidade de conhecerem essas realidades, socializarem seus saberes e, na interação com as comunidades, elaborarem propostas e criarem soluções participativas, de modo a atenuar as deficiências estruturais locais, contribuir para o bemestar dessas populações, e, simultaneamente, consolidar a formação dos universitários como cidadãos" [1].

**Atividades de extensão que constituam uma oportunidade da comunidade interagir com a Universidade, construindo parcerias que possibilitam a troca de saberes popular e acadêmico com aplicação de metodologias participativas. [4] 
Os extensionistas desenvolvem oficinas temáticas dentro das áreas da extensão universitária: comunicação, cultura, direitos humanos e justiça, educação, meio ambiente, saúde, tecnologia e produção, e trabalho.

As oficinas são desenvolvidas com base nas demandas socioambientais locais levantadas inicialmente pelo grupo a fim de determinar as potenciais questões a serem trabalhadas na comunidade. Nesta fase, cada oficina é descrita em documento que orienta as informações do saber a ser transmitido. São campos a serem preenchidos nesse documento: Justificativa para oficina, Público Alvo, Objetivos Específicos, Resumo de Aplicação, Carga Horária, Número de Participantes da oficina, Recursos e Materiais Necessários, Descrição Metodológica da Dinâmica, Duração, Resultados Esperados e Avaliação.

Em cada oficina é necessário o desenvolvimento de uma Dinâmica de fixação do conhecimento que utilize linguagens e métodos diferenciados, de acordo com o perfil do público alvo, o que permite contextualizar a demanda levantada e oferecer, de forma clara e objetiva, uma ou mais propostas de solução para a temática em questão. A dinâmica permite envolver acadêmicos e público interessado em uma construção coletiva do saber, tendo ao seu final uma reflexão acerca do conhecimento proposto pela oficina.

Há um direcionamento espontâneo das oficinas para a área temática ligada ao Meio Ambiente, o que acontece de forma natural em função do potencial acadêmico em trabalhar a temática, uma vez que os cursos do Centro de Ciências Agroveterinárias (CAV/UDESC) são vinculados à grande área Meio Ambiente, que possue demandas constantemente evidenciadas por lideranças comunitárias, por governantes e atores sociais locais e globais.

Após período de desenvolvimento interno, as oficinas são aplicadas em escola(s) pública(s), grupos da sociedade civil organizada e/ou entidades parceiras do projeto. Todas as oficinas são avaliadas posteriormente com relatório e debate interno ao grupo. Ao final de cada agenda de aplicação, cada oficina documentada e aplicada pelo Projeto Troca de Saberes é adicionada a um arquivo único que forma uma apostila que é disponibilizada ao grupo e ao NER, formando um acervo de trabalhos a serem utilizados por outros acadêmicos da universidade em ações futuras da UDESC.

***Tal relação tornou-se defasta para o ambiente quando a sociedade subordinou a natureza a uma lógica mercadológica. Esse processo de separação entre indivíduo e natureza, não a reconhecendo como legítima mas como um recurso, juntamente com as possibilidades acumuladas pela técnica e pela ciência, conduziu a um processo de crescimento industrial desordenado, intensificando os problemas ambientais, que atingem hoje um largo espectro, desde a dilapidação dos ecossistemas até o aumento da criminalidade [8].

\section{DISCUSSÃO}

\section{A Extensão Universitária e o Meio Ambiente}

O Centro de Ciências Agroveterinárias (CAV) possue em seus cursos de graduação e pós-graduação corpo docente e discente qualificado para desenvolver ações de Extensão Universitária na área temática Meio Ambiente, e também o compromisso de desenvolver essas atividades frente às demandas locais identificadas.

O meio ambiente e as relações socioambientais vem sendo foco de discussões e estudos pela atual geração, devido aos casos negativos resultantes da ação humana sobre os recursos naturais. Neste sentido, buscam-se soluções para problemas ambientais a partir da reflexão e atitudes que resultem em mudanças dos hábitos negativos impostos pelo capital e pela política do produtivismo em sua atual e influente relação com o meio ambiente ${ }^{* * *}[8]$. 
O potencial de contribuição das universidades com projetos locais é enorme, atualmente existem cerca de 5 milhões de estudantes universitários (Dados do Censo de Educação, INEP). Se cada estudante dedicar parte de seus estudos em atividade sociais, seria possível, por meio da extensão universitária, desenvolver inúmeras atividades socialmente engajadas que contribuiriam para a melhoria dos problemas brasileiros ${ }^{* * * *}$ [12]. É o que afirma Lucas Maciel Ramalho, especialista em Políticas Públicas e Gestão Governamental, coordenador do Programa de Extensão Universitária do Ministério da Educação [7].

O projeto Troca de Saberes identifica essa oportunidade e aposta na extensão universitária como contribuinte para a consolidação de uma sociedade que detenha hábitos e ações mais sustentáveis. A educação ambiental baseada em valores humanos e na valorização do meio ambiente é o caminho para essa meta global, conforme entende o documento das Nações Unidas "O Futuro que Queremos" nos parágrafos 229; 233; 251, desenvolvidos na Conferência das Nações Unidas sobre o Desenvolvimento Sustentável $(\mathrm{RIO}+20)$, respectivamente expostos ${ }^{* * * *}[11]$.

\section{A Extensão Universitária e a Formação Acadêmica}

A extensão universitária do projeto Troca de Saberes permite a expansão dos horizontes do pensamento ao colocar acadêmicos em contato com experiências que os fazem refletir profundamente sobre valores e aspectos da dinâmica social ${ }^{* * * * *}$. O projeto confirma a presença da academia na comunidade, dando ao estudante a oportunidade de ter uma experiência de aprendizado que vai além da cadeira acadêmica em uma relação direta com a sociedade, como explica Freire (1983) [6].

As demandas locais trabalhadas em oficinas estimulam a construção coletiva de saberes que beneficiarão: a comunidade, ao fomentar o raciocínio para solução do tema proposto, e o acadêmico, pelo fato de possibilitar a visão da problemática a partir de um ângulo diferenciado, o que contribui para um melhor entendimento de questões socioambientais que poderão, posteriormente, ser seu objeto de estudo no meio acadêmico ou na vida profissional. São experiências diferentes para cada voluntário, mas

\footnotetext{
*****Reafirmamos nosso compromisso com o direito à educação e, nesse sentido, comprometemo-nos a reforçar a cooperação internacional para alcançar o acesso universal à educação primária, especialmente para países em desenvolvimento. Reafirmamos ainda que o acesso pleno à educação de qualidade em todos os níveis é uma condição essencial para alcançar o desenvolvimento sustentável [...]. (RIO+20, 2012).

Tomamos a decisão de promover a Educação para o Desenvolvimento Sustentável e integrar o desenvolvimento sustentável mais ativamente na educação para além da Década das Nações Unidas da Educação para o Desenvolvimento Sustentável (2005-2014). (RIO+20, 2012)
}

Reconhecemos que há uma necessidade de informação global, integrada, e com bases científicas, sobre o desenvolvimento sustentável. [...] [...] Também nos comprometemos a mobilizar recursos financeiros e capacitação, particularmente para países em desenvolvimento, para garantir o sucesso dessa iniciativa. (RIO+20, 2012).

******[...] A eficácia do trabalho extensionista está em fornecer um modelo pelo qual é possível observar a realidade. A realidade, por sua vez, nos fornece elementos para teorizar, e a teoria nos fornece elementos para expandir a análise da realidade [...]" [9].
****Esta ação transformaria a educação superior em um verdadeiro vetor de melhoria da qualidade de vida da população. 


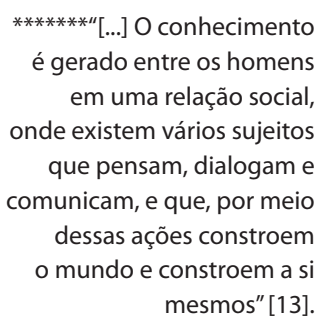

********Para a formação do profissional cidadão, é imprescindível sua interação com a sociedade por meio da extensão, seja para ele "se situar historicamente, para se identificar culturalmente e/ou para referenciar sua formação técnica com problemas que um dia terá que enfrentar"

[10]. que possuem um denominador comum, o sentimento de contribuição social ${ }^{* * * * * * *}$. As falas dos estudantes que participaram do projeto são confirmadas por suas experiências particulares que vão ao encontro com o que o projeto busca e os teóricos observam.

"a todo o momento houve troca de experiências e histórias entre o público alvo e os universitários";

"pode-se notar um grande interesse dos participantes pelo tema Meio Ambiente. No decorrer da Oficina houve uma troca de conhecimentos muito positiva”;

"creio que o momento foi de extrema aprendizagem para todos".

Tais experiências oferecem ao acadêmico a oportunidade de se reafirmar nas suas escolhas ${ }^{* * * * * * * *}$.

\section{RESULTADOS}

Entre 2012 e julho de 2013, foram realizadas 31 atividades, sendo 11 trabalhos desenvolvidos no primeiro semestre de 2012, 14 no segundo semestre, e 6 no primeiro semestre de 2013. A temática Meio Ambiente, com 58,0\% das oficinas aplicadas, teve maior aplicação dentre outras áreas associadas à proposta pedagógica do projeto, como a Educação, com 29,0\%, e a Saúde, com 12,9\% dos trabalhos aplicados. Os diferentes cursos de Graduação envolvidos no projeto formaram uma equipe multidisciplinar com distintas formações e conhecimentos, o que tornou possível abranger diferentes demandas socioambientais. Houve um sutil destaque na participação do curso de Engenharia Ambiental em relação aos outros cursos do Centro, como mostra o Gráfico 1.

Gráfico 1- Graduandos Participantes do Projeto por Curso

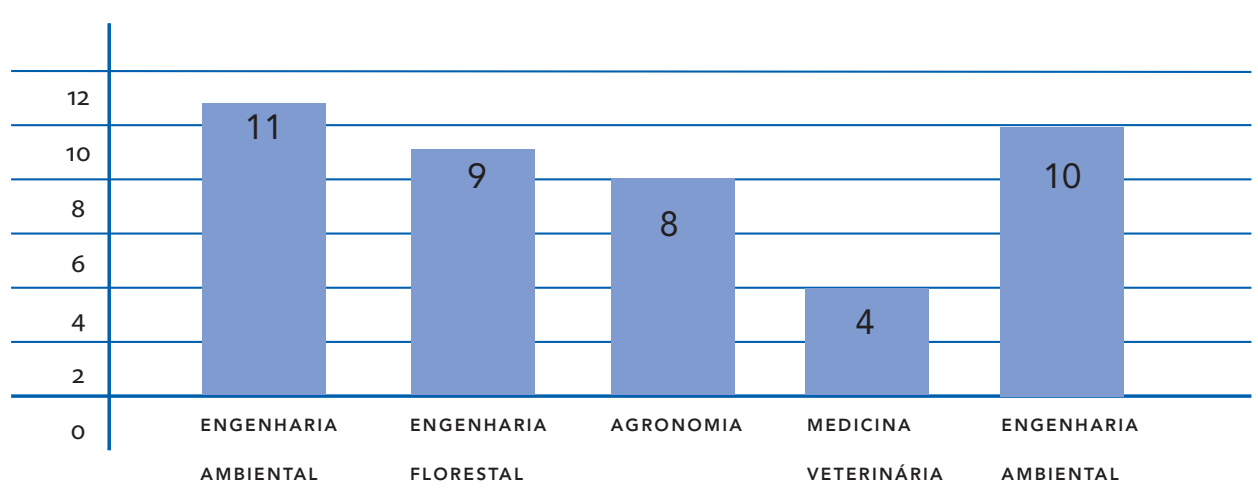


O projeto contemplou diferentes públicos com diversas faixas-etárias, tendo maior direcionamento de suas oficinas para alunos entre o e 5 anos de idade no primeiro semestre de 2012 e entre 6 e 11 anos no segundo semestre de 2012. Além desses contemplados, alunos com idade entre 12 e 17 anos participantes do Programa Ensino Médio Inovador do Ministério da Educação (ProEMI - MEC) [2], receberam oficinas no primeiro semestre de 2013, e alunos do Projeto Educação Jovens e Adultos (EJA), com faixa-etária entre 18 e 59 anos tiveram grande expressão numérica no somatório dos dois semestres iniciais do projeto. São os grupos, divididos por faixa etária, conforme o Gráfico 2.

Gráfico 2 - Público Recebedor do Projeto por faixa Etária e Semestre

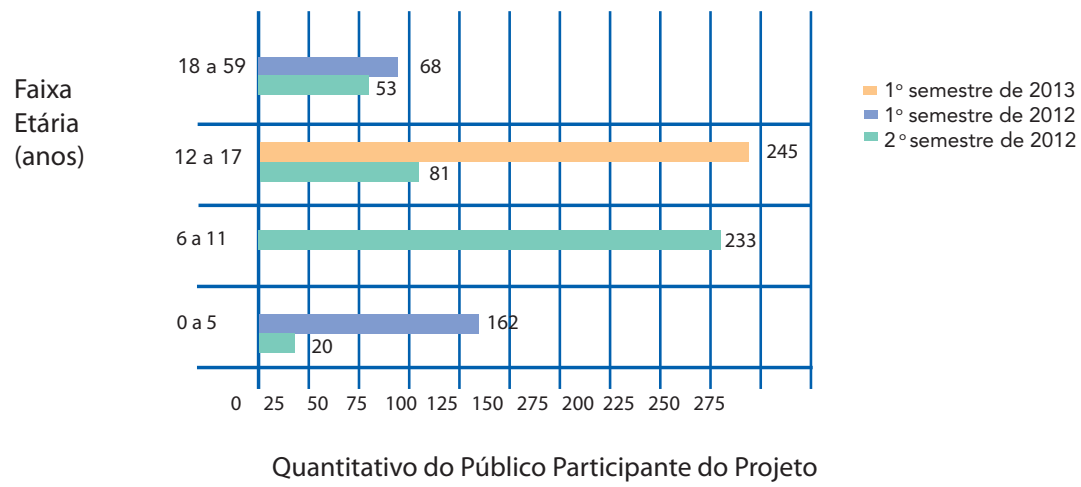

Durante o período de aplicação do projeto, a temática Meio Ambiente envolveu 444 estudantes. A segunda grande área mais trabalhada foi a de Educação, que recebeu, em oficinas, 302 participantes. A temática Saúde, também de grande relevância no contexto local, recebeu 116 alunos em oficinas, como sintetiza o Gráfico 3.

Gráfico 3 - Público Recebedor do Projeto por Área Temática

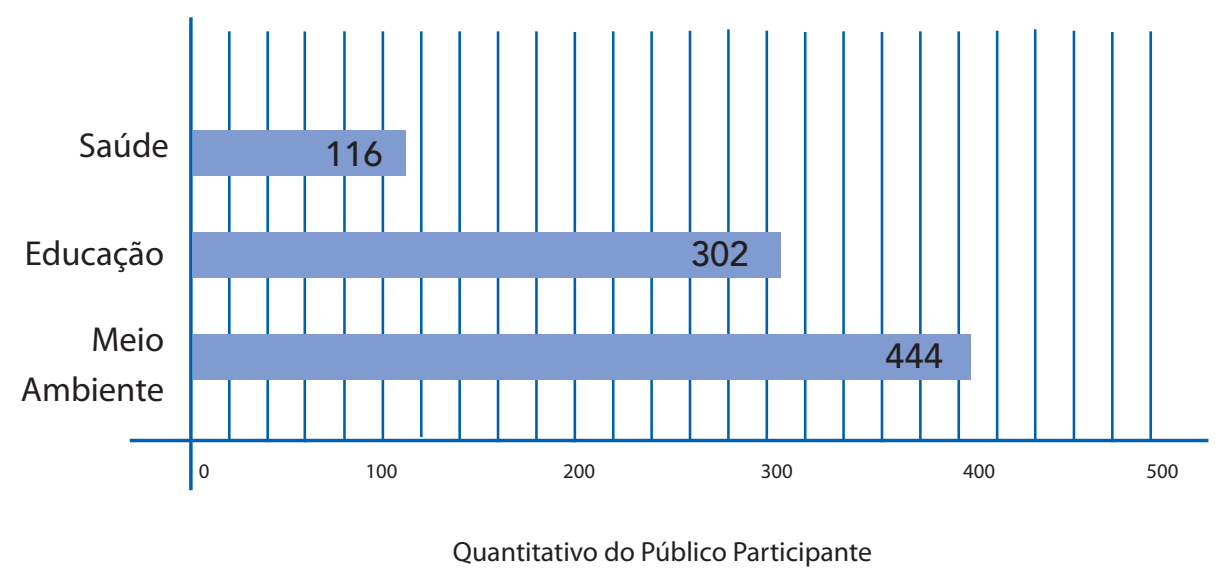




\section{CONCLUSÃO}

O projeto esteve, até o momento, em contato com a sociedade através de escolas públicas do município de Lages/SC e da escola Serviço Social da Indústria (SESI). Em suas atividades, o projeto sempre visou proporcionar aos estudantes o conhecimento de distintas realidades em suas relações com os públicos alvos e com os locais de aplicação. As abordagens das oficinas aplicadas foram além dos seus títulos e conteúdos de base, expandindo-se em assuntos contextualizados com a temática central da oficina, assuntos que, na maioria das vezes, foram levantados pelo público alvo conhecedor da problemática, pois este já a percebeu através de sua vivência cotidiana e/ou em situações distintas.

Dessa forma, observou-se uma pré-disposição da sociedade em debater situações de seu interesse, sendo essas discussões orientadas e amparadas tecnicamente pelos acadêmicos. Tais debates e reflexões se fizeram positivos e construtivos junto ao público alvo que, conduzidos ao entendimento do objeto de estudo, se autodeclarou conscientizado. Nesse sentido, o trabalho realizado sempre esteve comprometido com os princípios de uma extensão universitária emancipatória, multidisciplinar e conectada com uma construção coletiva do saber, colocando em prática o papel e compromisso da universidade pública para com a sociedade que a financia. O projeto beneficiou ,entre 2012 e 2013, um total de 862 pessoas.

\section{REFERÊNCIAS}

[1] BRASIL. Ministério da Defesa. Projeto Rondon. Disponível em: <http://www. defesa.gov. br/projeto_rondon>. Acesso em: 20 jun. 2011.

[2] BRASIL. Ministério da Educação (MEC). Projeto Ensino Médio Inovador ProEMI. Disponível em: <http://portal.mec.gov.br/index.php?option=com content\&view=article\&id=13439>. Acesso em: 10 mar. 2013.

[3] BRASIL. Plano das Nações Unidas para o Desenvolvimento no Brasil (PNUD). Atlas de Desenvolvimento Humano 2013. Disponível em: $<$ http://www.atlasbrasil.org.br/2013/download>. Acesso em 1 de ago. de 2013.

[4] CONSELHO DE ENSINO, PESQUISA E EXTENSÃO (CONSEPE) da Universidade do Estado de Santa Catarina (UDESC). RESOLUÇÃO No o26/2012 - CONSEPE. Disponível em: <http://secon.udesc.br/consepe/resol/2012/o262012-cpe.pdf $>$. Acesso em 10 de mar. de 2013.

[5] FÓRUM NACIONAL DE PRÓ-REITORES DE EXTENSÃO DAS UNIVERSIDADES PÚBLICAS BRASILEIRAS. Avaliação Nacional da Extensão Universitária 200o. Disponível em: <http://www.unifal-mg.edu.br/extensao/files/ file/colecao_extensao_univeristaria/colecao_extensao_universitaria_3_avaliacao.pdf $>$. Acesso em: 8 de fev. de 2013.

[6] FREIRE, P. Extensão ou Comunicação? Rio de Janeiro: Paz e Terra, 1983.

[7] MACIEL, L. R. Política Nacional de Extensão: Perspectivas para a Universidade Brasileira. Brasília: Universidade de Brasília, 2010.

[8] MELO, M. M. de. Capitalismo versus Sustentabilidade: o desafio de uma nova 
ética ambiental. Florianópolis: Universidade Federal de Santa Catarina, 2006.

[9] MORIN, E. Da necessidade de um pensamento complexo. Tradução de Juremir Machado Silva. In: MARTINS, F. M.; SILVA, J. M (Orgs.). Para navegar no século XXI: tecnologias do imaginário e cibercultura. Porto Alegre: Sulinas/ Edipucrs, 2003.

[10] NOGUEIRA, M. das D. P. (Org.). Extensão universitária: diretrizes conceituais e políticas. Belo Horizonte: UFMG, 2000.

[11] ONU. RIO+2o - Conferência das Nações Unidas sobre o Desenvolvimento Sustentável - Declaração Final da Conferência das Nações Unidas sobre Desenvolvimento Sustentável (RIO+2o): O Futuro que Queremos. Rio de Janeiro, 2012.

[12] REVISTA PARTICIPAÇÃO. 90 anos de Paulo Freire. Brasília: Universidade de Brasília; Decanato de Extensão, 1997.

[13] SANTOS, A. B. Extensão Universitária como Viabilizadora de Políticas Públicas: A Visão de Acadêmicos da UDESC. Dissertação (Mestrado em Gestão de Políticas Públicas) - Universidade do Vale do Itajaí, Itajaí, 2012.

[14] UNIVERSIDADE DO ESTADO DE SANTA CATARINA (UDESC). Núcleo Extensionista RONDON - NER. Disponível em: < www.udesc.br/ner > . Acesso em: o8 jul. 2013.

GUILHERME DA SILVA RICARDO graduando do curso de Engenharia Ambiental do Centro de Ciências Agroveterinárias da Universidade do Estado de Santa Catarina (CAV/UDESC) - e-mail: guilhermericardo@terra.com.br

ÁlVARO LUIZ MAFRA professor associado ddo Centro de Ciências Agroveterinárias da Universidade do Estado de Santa Catarina (CAV-UDESC) - e-mail:azalm@cav.udesc.br 